\title{
Disentangling the Effect of Adult Biomass and Temperature on the Recruitment Dynamics of Fishes
}

\author{
Massimiliano Cardinale, Joakim Hjelm, \\ and Michele Casini \\ National Board of Fisheries, Institute of \\ Marine Research, Lysekil, Sweden
}

\section{Abstract}

Here we analyzed the relation between recruitment dynamic (recruitment or recruitment success) and temperature of 57 commercial fish stocks of the North Atlantic. We showed that, although the effect of temperature was generally significant, spawning biomass is the main factor governing recruitment dynamic. A significant effect of spawning biomass was evident for $67 \%$ of all stocks analyzed in this study. For gadoids, the effect of spawning biomass was larger than the effect of temperature (both in terms of number of stocks and proportion of variance explained). For clupeids, spawning biomass was more important than temperature for a higher number of stocks, but the strength of the two effects, when present, was similar. Also, stocks living in colder and warmer areas showed, respectively, a positive and negative response to temperature for both families. Our results highlight that failing to account for spawning biomass effect in climate-recruitment studies could mask the influence of climate variability on recruitment dynamic. In this context, although management of several exploited fish populations cannot be entirely decoupled from the effect of climate on stock reproductive success, it is likely that the observed changes in exploited fish population dynamics are mainly the consequences of an unsustainable human impact and not climate changes.

\section{Introduction}

The physical environment has been long recognized as an essential factor in the regulation of fish population in marine ecosystems (Cushing 
1982, Steele 1985). Among environmental factors, temperature is often the principal variable investigated since it regulates the rate in many ecological and physiological processes (Brett 1979). Therefore, there are strong justifications for studying the link between fish recruitment and temperature, and this information may be crucial for the management of marine resources and to predict the long-term consequence of climate changes on fisheries (Myers 1998). It is now recognized that the twenty-first century will show a significant global warming trend induced by an increase in atmospheric greenhouse effect (Houghton et al. 2001). This will also imply that a global change in the oceanic climate may propagate to the upper level of the food webs (Sarmineto et al. 1998) and consequently affect important marine resources (i.e., Loukos et al. 2003, Drinkwater 2005). Therefore, there is an increasing interest on the relation between climate and fisheries, both at the ecological and economic level (Bopp et al. 2001, Eide and Heen 2002), and evidence suggests that there is a direct link between climate and fish population dynamics (Marshall et al. 2001, Bakun and Broad 2002). In this context, life history traits might constitute a powerful means to unravel the interaction between climate and fish population. Among those, the number of recruits per unit of spawning stock biomass (SSB), i.e., the stock recruitment success $\left(R_{s}\right)$, is one of the most important parameter proxies for population productivity (MacKenzie et al. 2003, Stige et al. 2006).

In this study we explored recruitment data in relation to spawning stock biomass and temperature for exploited fish stocks in the North Atlantic - 57 selected demersal gadoids (cod, Gadus morhua; haddock, Melanogrammus aeglefinus; saithe, Pollachius virens; and whiting, Merlangius merlangus) and pelagic clupeids (herring, Clupea harengus; and sprat, Sprattus sprattus). Common patterns in life histories and population dynamics are evident only after data from several stocks, species, and areas are combined and standardized in ways that enable fair and unbiased comparisons (Myers 1998, MacKenzie et al. 2003). First, we revised available information to disentangle the effect of spawning stock biomass and temperature on $R_{s}$ for the selected stocks. Successively, we investigated the potential differences in the strength and sign of these effects between families (gadoids and clupeids) and areas. We deliberately limited the analysis to SSB and temperature, although we were aware that other abiotic factors (i.e., precipitation, wind direction, currents, ice cover, etc.) and biotic factors (i.e., predation, competition, stock structure, food availability, fecundity, condition of the spawners, etc.) play an important role on recruitment processes. 


\section{Materials and methods Time series}

\section{Stock and recruitment data}

We compiled data of spawning stock biomass (SSB) and number of recruits $(R)$ available at the International Council for the Exploration of the Sea (ICES), www.ices.dk, at the Northwest Atlantic Fisheries Organization (NAFO), www.nafo.ca, and the Ransom Myers Web site, www.mscs.dal.ca/ myers/welcome.html (Table 1). For geographical distribution the reader can refer to www.ices.dk and www.nafo.ca. All estimates are derived from VPA (virtual population analysis) models and thus do not include any assumptions on the form of stock-recruitment curve.

\section{Temperature data}

The temperature data appropriate for comparisons of North Atlantic stocks should fulfill several requirements (Planque and Frédou 1999): they must be available for every stock, be consistent and sufficiently long, and correspond to large oceanic areas to be representative of the change in temperature experienced by the stock over its area of distribution. It is well known (see discussion in Ottersen et al. 1998) that environmental temperature does not strictly correspond to "ambient" temperature, although the population generally experiences higher temperature in warm years and vice versa (Planque and Frédou 1999). At the same time, it is likely that sea surface temperature (SST) reflects more closely ambient temperature of pelagic fish than demersal species. Anyhow, to accomplish all listed criteria, we used sea surface temperature data from the International Comprehensive Ocean Atmosphere Dataset (ICOADS) available at www.cdc.noaa.gov/coads/ coads_cdc_netcdf.shtml. Monthly average at the spatial resolution of 2 degrees of latitude and 2 degrees of longitude were available for all stocks from 1800. For each stock, we calculated the annual average (SST) and the average temperature of the time series at the geographical centroid of the stock distribution (SST-A) (available at www.mscs. dal.ca/ myers/welcome.html) (Table 1). The latter was used as a proxy for the mean ambient temperature occurring in the area of distribution of each stock.

\section{Statistical analysis}

To allow for stock comparisons, we chose to estimate $R$ as the number of age 1 individual. For those stocks for which the numbers of age 1 individuals were not available, the logistic equation (Hilborn and Walters 1992) was applied using values of natural and fishing mortality estimated for the adjacent age class. In order to make comparable spring and autumn herring spawners, the number of 1-year-old individuals of 
Table 1. List of the stocks used in this study with the stock acronyms, the fishing area as defined by ICES and NAFO, latitude and longitude corresponding to the centroid of the stock distribution, the geographical location (i.e., area, NEA = Northeast Atlantic; NWA $=$ Northwest Atlantic), and the age of recruitment to the fisheries and the period of available data. SST-A is the average temperature experienced by the stock in the time-series, measured at the centroid of the stock distribution.

\begin{tabular}{|c|c|c|c|c|c|c|c|}
\hline Acronym & $\begin{array}{l}\text { Fishing } \\
\text { area }\end{array}$ & Latitude & Longitude & Area & SST-A & $\begin{array}{l}\text { Age of } \\
\text { recruits } \\
\text { (year) }\end{array}$ & Years \\
\hline $\mathrm{CA}$ & I\&II & 68 & 15 & NEA & 7.6 & 3 & $1946-2003$ \\
\hline CEB & IIId & 56 & 19 & NEA & 8.8 & 2 & $1966-2003$ \\
\hline $\mathrm{CF}$ & $\mathrm{Vb}$ & 62 & -8 & NEA & 11.0 & 2 & $1961-2003$ \\
\hline CI & $\mathrm{Va}$ & 63 & -21 & NEA & 8.6 & 3 & $1955-2003$ \\
\hline CK & IIIa & 57 & 12 & NEA & 9.0 & 1 & $1971-2003$ \\
\hline CNS & IV & 55 & 4 & NEA & 9.9 & 1 & $1963-2003$ \\
\hline CWB & IIIc\&d & 55 & 13.5 & NEA & 8.8 & 1 & $1970-2003$ \\
\hline CVIA & VIa & 58.5 & -6 & NEA & 10.8 & 1 & $1966-2003$ \\
\hline CVIIA & VIIa & 54 & -5 & NEA & 10.8 & 0 & $1968-2003$ \\
\hline CVIIEK & VIIe-k & 51 & -5 & NEA & 13.0 & 1 & 1971-2003 \\
\hline $\mathrm{HA}$ & I\&II & 68 & 15 & NEA & 7.6 & 3 & $1950-2003$ \\
\hline $\mathrm{HF}$ & $\mathrm{Vb}$ & 62 & -8 & NEA & 11.0 & 2 & $1961-2003$ \\
\hline $\mathrm{HI}$ & $\mathrm{Va}$ & 63 & -21 & NEA & 8.6 & 2 & 1981-2003 \\
\hline HNS & IV & 55 & 4 & NEA & 9.9 & 0 & $1963-2003$ \\
\hline HVIB & $\mathrm{Vb}$ & 57.25 & -15 & NEA & 11.0 & 3 & $1985-2003$ \\
\hline SA & I\&II & 68 & 15 & NEA & 7.6 & 3 & $1960-2003$ \\
\hline SF & $\mathrm{Vb}$ & 62 & -8 & NEA & 11.0 & 3 & $1961-2003$ \\
\hline SI & $\mathrm{Va}$ & 63 & -21 & NEA & 8.6 & 3 & $1962-2003$ \\
\hline SNS & IIIa\&IV\&VI & 55 & 4 & NEA & 9.9 & 3 & $1967-2003$ \\
\hline WNS & IV & 55 & 4 & NEA & 9.9 & 1 & $1980-2003$ \\
\hline WVIA & VIa & 58.5 & -6 & NEA & 10.8 & 1 & $1978-2003$ \\
\hline WVIIA & VIIa & 54 & -5 & NEA & 10.8 & 1 & $1980-2003$ \\
\hline WVIIEK & VIIe-k & 51 & -5 & NEA & 13.0 & 0 & $1982-2003$ \\
\hline CESS & $4 \mathrm{~W}-4 \mathrm{Vs}$ & 44 & -59 & NWA & 8.8 & 1 & 1958-1993 \\
\hline CFC & $3 \mathrm{M}$ & 47 & -45 & NWA & 8.4 & 1 & $1972-2001$ \\
\hline CG & 1 & 59 & -44 & NWA & 5.4 & 3 & 1952-1992 \\
\hline CGEO & $5 Z e$ & 41 & -67 & NWA & 12.8 & 1 & 1977-1998 \\
\hline CLAB & $2 \mathrm{~J}-3 \mathrm{KL}$ & 50 & -52 & NWA & 4.1 & 3 & 1959-1992 \\
\hline CNSL & $3 P n-4 S R$ & 49 & -60 & NWA & 5.7 & 3 & 1974-1997 \\
\hline CSGB & $3 \mathrm{NO}$ & 44.5 & -51.5 & NWA & 8.5 & 3 & 1956-1993 \\
\hline CSSL & $4 \mathrm{~T}-\mathrm{Vn}$ & 47.5 & -63.5 & NWA & 6.2 & 3 & 1947-1993 \\
\hline CSTP & 3Ps & 46 & -55.5 & NWA & 6.6 & 3 & 1956-1993 \\
\hline
\end{tabular}


Table 1. (continued.)

\begin{tabular}{|c|c|c|c|c|c|c|c|}
\hline Acronym & $\begin{array}{l}\text { Fishing } \\
\text { area }\end{array}$ & Latitude & Longitude & Area & SST-A & $\begin{array}{l}\text { Age of } \\
\text { recruits } \\
\text { (year) }\end{array}$ & Years \\
\hline CWSS & $4 X$ & 43 & -65.5 & NWA & 9.4 & 1 & 1948-1994 \\
\hline HGEO & $5 Z e$ & 41 & -67 & NWA & 12.8 & 1 & 1931-1998 \\
\hline HWSS & $4 X$ & 43 & -65.5 & NWA & 9.4 & 1 & 1970-1998 \\
\hline SESS & $4 \mathrm{VWX} 5 \mathrm{Zc}$ & 44 & -59 & NWA & 8.8 & 1 & $1982-2002$ \\
\hline $\mathrm{HCB}$ & $\begin{array}{l}\text { IIId (SDs25- } \\
\text { 29) }\end{array}$ & 57 & 21 & NEA & 8.8 & 1 & $1974-2003$ \\
\hline HCS & VIIe-j & 51 & -5 & NEA & 12.9 & 1 & $1958-2003$ \\
\hline HGR & IIId (SD 32) & 57.3 & 23.4 & NEA & 7.9 & 1 & $1977-2003$ \\
\hline HIS & VIIaN & 54 & -4.5 & NEA & 10.8 & 1 & $1961-2003$ \\
\hline HISS & $\mathrm{Va}$ & 63 & -21 & NEA & 8.6 & 2 & $1981-2003$ \\
\hline HNBB & IIId (SD 31) & 65 & 23 & NEA & 6.9 & 1 & $1980-2003$ \\
\hline HNSAS & IV\&VIId\&IIIa & 58 & 2 & NEA & 9.9 & 1 & $1960-2003$ \\
\hline HNSS & II\&IVa & 65 & 8 & NEA & 8.8 & 1 & $1950-2003$ \\
\hline HSBB & IIId (SD 30) & 62 & 20 & NEA & 6.4 & 1 & $1973-2003$ \\
\hline HWBSS & $\begin{array}{l}\text { IIIa\&SDs } \\
22-24\end{array}$ & 55 & 12 & NEA & 8.8 & 1 & $1991-2003$ \\
\hline HWI & Via(S)\&VIIb-c & 54.3 & -12 & NEA & 12.1 & 1 & $1970-2003$ \\
\hline HWS & Via $(\mathrm{N})$ & 57 & -9 & NEA & 11.1 & 1 & $1958-2003$ \\
\hline SBS & IIIb-d & 57 & 21 & NEA & 8.8 & 1 & $1974-2003$ \\
\hline SNS & IV & 58 & 2 & NEA & 9.9 & 1 & $1984-2003$ \\
\hline HNFBBTB & $3 \mathrm{KL}$ & 48.25 & -52.45 & NWA & 5.5 & 2 & $1971-2002$ \\
\hline HNFMBPB & $3 \mathrm{KL}$ & 46.4 & -54 & NWA & 6.3 & 2 & $1970-2002$ \\
\hline HNFWBNB & $3 \mathrm{KL}$ & 50 & -55 & NWA & 4.9 & 2 & $1971-2002$ \\
\hline HSSLAS & $4 \mathrm{~T}$ & 47 & -63 & NWA & 6.3 & 2 & $1978-2002$ \\
\hline HSSLSS & $4 \mathrm{~T}$ & 47 & -63 & NWA & 6.3 & 2 & $1978-2002$ \\
\hline HWNFSS & $4 \mathrm{R}$ & 49.25 & -59 & NWA & 5.4 & 2 & $1965-2002$ \\
\hline HWNSAS & $4 \mathrm{R}$ & 49.25 & -59 & NWA & 5.4 & 2 & $1965-2002$ \\
\hline
\end{tabular}


spring spawner stocks was negatively adjusted for a natural mortality of 0.075 per month for 2 months as in Toresen (2001).

The annual stock-specific recruitment success $\left(R_{s}\right)$ was estimated for each stock and year as the natural logarithm of the ratio between $R_{y}$ and $S S B_{y-1}$ (Hilborn and Walters 1992, Beverton 2002). We are aware that SSB does not completely reflect the reproductive potential of a stock. For example, stock structure (i.e., proportion of older individuals, see Marshall et al. 1998; Cardinale and Arrhenius 2000) and/or variability in fecundity or condition of the spawners (e.g., Olsen et al. 2005, Scott et al. 2006) are not included in SSB estimation, although they are known to affect the reproductive output of the stock. However, SSB is the only estimate of the reproductive potential that is available for every stock, has a sufficiently long time series, and is consistently calculated to allow for comparisons among North Atlantic fish species.

Here we followed the procedure suggested by Cardinale and Hjelm (2006) and Stige et al. (2006). The first step is to test for and disentangle the SSB effect on $R$. In one of his last lectures at Woods Hole, Beverton (2002) suggested an approach for exploring this relationship. Because of the biological mechanisms behind the classical $S S B-R$ relationships, recruitment success $\left(R_{s}\right)$ should improve as SSB decreases (Fig. 1 in Cardinale and Hjelm 2006). However, if recruitment is also mediated by physical environmental events, this negative relationship may not be as obvious. For example, when the stock is declining, a negative effect of climate on $R$ will result in a decrease in $R_{s}$; this is reversed in the case of a positive effect of climate on $R$. Therefore, the variability around the relationship between $R_{s}$ and $S S B$ can be considered as a proxy for recruitment anomalies $\left(R_{a}\right)$ and it is assumed to be partially determined by the stochasticity in the physical environment (Beverton 2002). However, it is worth it to emphasize that $R_{a}$ can be used in climate-recruitment analysis only when a significant effect of SSB on $R_{s}$ can be demonstrated. Conversely, when SSB has no significant effect on $R_{s}$, climate variables can be directly correlated to recruitment $(R)$. It is also important to highlight that, if $S S B$ has no effect on $R_{s}$, using $R_{a}$ instead of $R$ can actually mask any recruitment-climate relationship. The rationale behind these assumptions is mathematically formalized in the classical Ricker (1954) or Beverton and Holt (1995) recruitment functions, which are in turn based on sound ecological mechanisms (e.g., cannibalism and predation). Being that $R_{s}$ is an index of recruitment scaled by $S S B$, the properties of $R$ and $R_{s}$ and their relationships with SSB are mathematically very different and cannot be directly compared.

The number of recruits in a fish species is generally related to egg production or SSB that is, in turn, considered a proxy of egg production (Myers and Barrowman 1996). Thus, we fitted a simple deterministic linear model: 

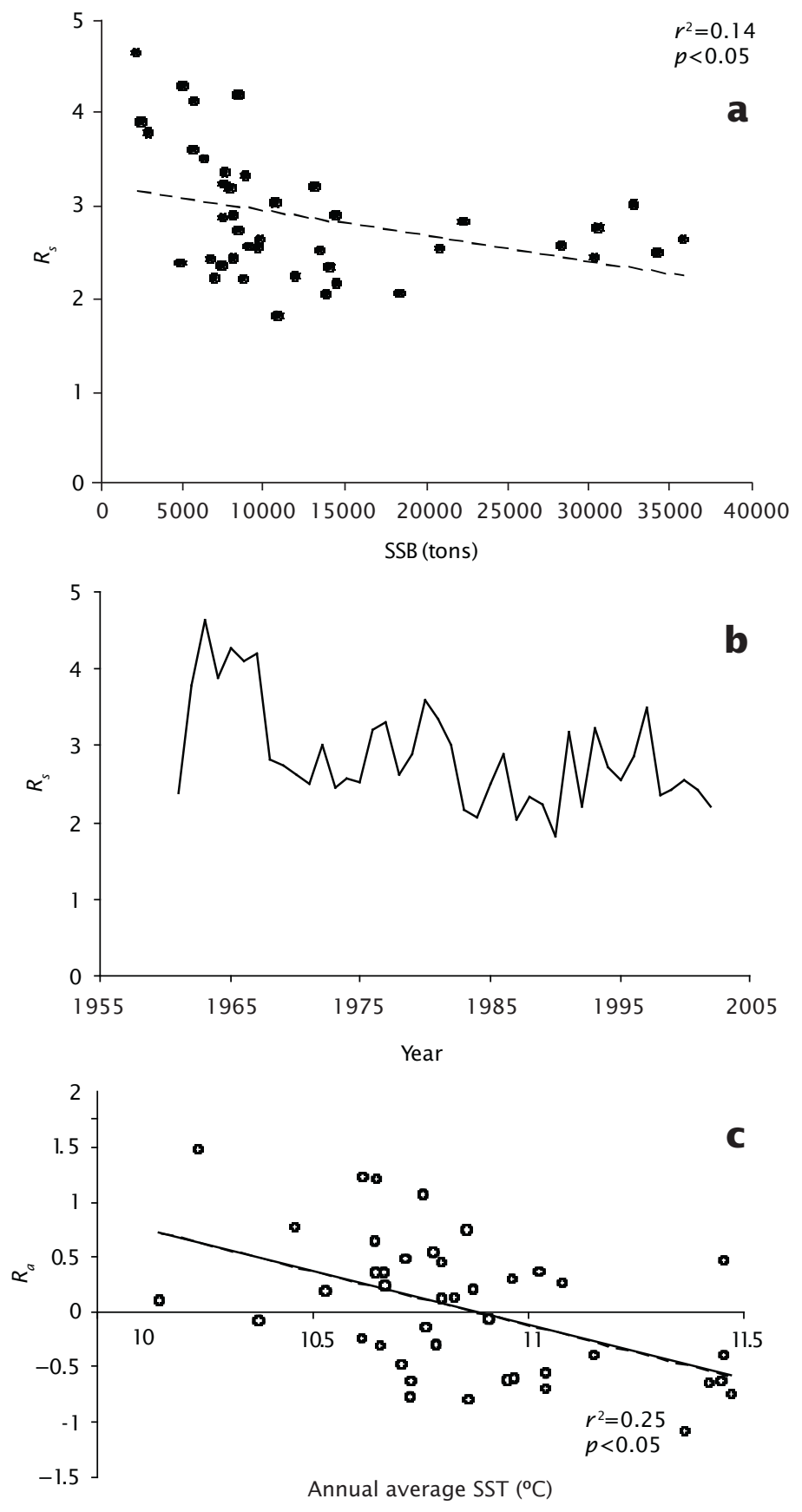

Figure 1. Example (Irish Sea herring stock) of the procedure used in the analysis. (a) relationship $R_{s}$-SSB with residuals $\left(R_{a}\right)$; (b) trends in $R_{a}$ over time, and (c) relationship $R_{a}-S S T$. 


$$
R_{s}=\alpha-\beta \times S S B \quad \text { (Eq. } 1 \text {. }
$$

For those stocks where the slope of $\beta$ was significantly different from 0 , the residuals were estimated. The residuals from Eq. 1 are defined hereafter as annual recruitment anomalies $\left(R_{a}\right) . R_{a}$ values were successively tested for correlation with annual average SST for each stock. For those stocks where the relationship between $R_{s}$ and $S S B$ was not significant, the relationships between $R$ (in numbers of individuals) and SST were tested fitting a simple deterministic linear model as for Eq. 1. Trends in $R_{a}$ and $R$ are defined as recruitment dynamic thereafter. An example of the procedure described above is shown in Fig. 1 for the Irish Sea herring stock.

In our analysis we also investigated the following.

1. The proportion of stocks with an effect of SSB on $R_{s}$ and the proportion of stocks with an effect of SST on $R_{a}$ (or $R$ for those stocks where an SSB effect was not evident). Differences between and within families were calculated using the Fisher exact test.

2. The strength (i.e., $r^{2}$ in absolute terms) of the effect of SSB on the $R_{s}$ and of the effect of SST on $R_{a}$ (or $R$ for those stocks where an SSB effect was not evident). Differences between and within families were calculated using the Kruskall-Wallis test.

We also investigated the proportion of stocks with a positive sign in the effect of SST on $R_{a}$ (or $R$ for those stocks where an SSB effect was not evident) and the difference in the strength of the SSB effect compared to that of SST between and within families.

Finally, we plotted the $r^{2}$ of those stocks for which a significant effect of SST on $R_{a}$ (or $R$ for stocks where an SSB effect was not found) was demonstrated against the average ambient temperature in the area of distribution of each stock during the time series (SST-A) for gadoids and clupeids separately.

The models used do not take temporal autocorrelation into account. The level of significance was set at $5 \%$ for all the statistical tests used in this study. Statistical analysis was performed using S-PLUS (Insightful Corporation 2005) and Statistica (Statsoft Inc. 2003) computer software.

\section{Results}

There were no statistically significant differences (Fisher exact test) between families (gadoids against clupeids) in the proportion of stocks with an SSB effect on $R_{s}$ (test 1 ) as well as a SST effect on $R_{a}$ (or $R$ depending on the stocks) (test 2; Table 2). There was also no statistical 
Table 2. Results of the Fisher exact test. Between: between-family (gadoids and clupeids) differences in the proportion of stocks with an effect of SSB on $R_{s}$ (test 1 ), in the proportion of stocks with an effect of SST on $R_{a}($ or $R)$ (test 2), and in the sign of the effect of SST on $R_{a}($ or $R$ ) (test 3). Within: within-family (gadoids and clupeids) differences in the proportion of stocks with an effect of SSB on $R_{s}$ compared to the effect of SST on $R_{a}$ (or $R$ ) (tests 4 and 5). All stocks: differences in the proportion of stocks with an effect of SSB on $\boldsymbol{R}_{s}$ compared to the effect of SST on $\boldsymbol{R}_{a}$ (or $R$ ) (test 6); $p$ is the significance value of the tests and $n$ the number of stocks used in the analysis.

\begin{tabular}{|c|c|c|c|c|c|c|c|}
\hline \multicolumn{8}{|c|}{ Fisher test } \\
\hline & & Variable & Gadoids & Clupeids & $p$ & $n$ & Test \\
\hline \multirow{3}{*}{ 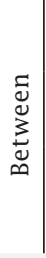 } & & $\begin{array}{l}\text { Proportion of stock with an } \\
\text { effect of } S S B \text { on } R_{s}\end{array}$ & $61 \%$ & $76 \%$ & 0.27 & 38 & 1 \\
\hline & & $\begin{array}{l}\text { Proportion of stock with an } \\
\text { effect of } S S T \text { on } R_{a} \text { (or } R \text { ) }\end{array}$ & $31 \%$ & $29 \%$ & 0.87 & 17 & 2 \\
\hline & & $\begin{array}{l}\text { Proportion of stocks with a } \\
\text { positive effect of } S S T \text { on } R_{a} \\
\text { (or } R \text { ) }\end{array}$ & $36 \%$ & $67 \%$ & 0.24 & 17 & 3 \\
\hline \multirow{3}{*}{ 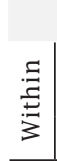 } & & & $S S B$ & SST & & & \\
\hline & Gadoids & $\begin{array}{l}\text { Proportion of stocks with } S S B \\
\text { compared to } S S T \text { effect }\end{array}$ & $61 \%$ & $31 \%$ & $<0.01$ & 33 & 4 \\
\hline & Clupeids & $"$ & $76 \%$ & $29 \%$ & $<0.001$ & 22 & 5 \\
\hline \multicolumn{2}{|c|}{ All stocks } & $"$ & $69 \%$ & $31 \%$ & $<0.001$ & 55 & 6 \\
\hline
\end{tabular}

difference between families concerning the sign of SST effect on $R_{a}$ (or $R$ depending on the stocks) (test 3).

On the other hand, there was a statistical difference in the proportion of stocks with an SSB effect on $R_{s}$ compared to those with an SST effect on $R_{a}$ (or $R$ ) for both gadoids and clupeids (tests 4 and 5) with a statistically larger proportion of stocks with a SSB effect on $R_{s}$ (tests 4-6; Table 2).

There was no difference (Kruskall-Wallis test) concerning the strength of the SSB effect on $R_{S}$ (test 7) and SST effect on $R_{a}$ (or $R$ depending on the stocks) (test 8 ) between families (Table 3). On the other hand, there was a statistical difference in the strength of the SSB effect compared to the SST effect for gadoids (test 9) and for all stocks combined (test 11), while the same was not found for clupeids (test 10; Table 3).

We plotted the $r^{2}$ of the $S S T$ effect on $R_{a}$ (or $R$ ) against the average temperature in the area of distribution of each stock during the time series (SST-A) (see Table 1). Only those stocks where a significant effect of SST on recruitment dynamic was found were used (see Table 4). The 
Table 3. Results of the Kruskall-Wallis test. Between: between-family (gadoids and clupeids) difference in the strength $\left(r^{2}\right)$ of the effect of SSB on $R_{s}$ (test 7) and in the strength of the effect of SST on $R_{a}$ (or $R$ ) (test 8). Within: within-family (gadoids and clupeids) differences in the strength of the effect of SSB on $R_{s}$ compared to the strength of the effect of SST on $R_{a}($ or $R)$ (test 9 and 10). All stocks: differences in the strength of the effect of SSB on $R_{s}$ compared to the strength of the effect of SST on $R_{a}($ or $R)$ (test 11). The strength of the relationships is shown as median of $r^{2} ; p$ is the significance value of the tests and $n$ the number of stocks used in the analysis.

\begin{tabular}{|c|c|c|c|c|c|c|c|}
\hline \multirow{4}{*}{ 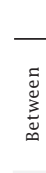 } & & & \multicolumn{5}{|c|}{ Kruskall-Wallis test } \\
\hline & & Strength $\left[r^{2}\right]$ & Gadoids & Clupeids & $p$ & $n$ & Test \\
\hline & & Effect of $S S B$ on $R_{s}$ & 0.31 & 0.33 & 0.89 & 38 & 7 \\
\hline & & Effect of $S S T$ on $R_{a}$ (or $R$ ) & 0.16 & 0.26 & 0.61 & 17 & 8 \\
\hline \multirow{4}{*}{ 量 } & & & $S S B$ & SST & & & \\
\hline & Gadoids & $S S B$ compared to $S S T$ effect & 0.31 & 0.16 & $<0.01$ & 33 & 9 \\
\hline & Clupeids & $"$ & 0.33 & 0.26 & 0.25 & 22 & 10 \\
\hline & All stocks & $"$ & 0.32 & 0.19 & $<0.01$ & 55 & 11 \\
\hline
\end{tabular}

analysis showed that stocks living in colder areas present a positive effect of SST on $R_{a}$ (or $R$ ), and vice versa, for both families (Fig. 2).

\section{Discussion}

Recruitment $(R)$ is considered generally related to egg numbers or stock spawning biomass ( $S S B$ ) (a proxy for egg numbers) (Myers and Barrowman 1996) and this was confirmed in our study by the fact that a significant effect of SSB on recruitment success $\left(R_{s}\right)$ was evident for $67 \%$ of all stocks analyzed. This again highlights that failing to account for the SSB effect in climate-recruitment studies could mask the influence of climate variability on recruitment dynamic (Myers 1998, Cardinale and Hjelm 2006). Therefore, our approach, as advocated by Beverton (2002) and previously used by Cardinale and Hjelm (2006) and Stige et al. (2006), is able to unravel stock productivity and climate by using the deviation from the theoretical relation between SSB and $R_{s}$. During the last decade, most of the published papers on meta-analysis of fish and climate (for instance, see ICES Journal of Marine Science 58(5) and 62(7) and references herein) have used some climate proxy to explain observed variability in $R$ or $R_{s}$ without exploring and disentangling the effect of adult biomass on recruitment. This makes difficult a comparison between previous studies and our analysis (see Cardinale and Hjelm 2006 for a useful discussion). Also, $R_{s}$ and recruitment is not the same 

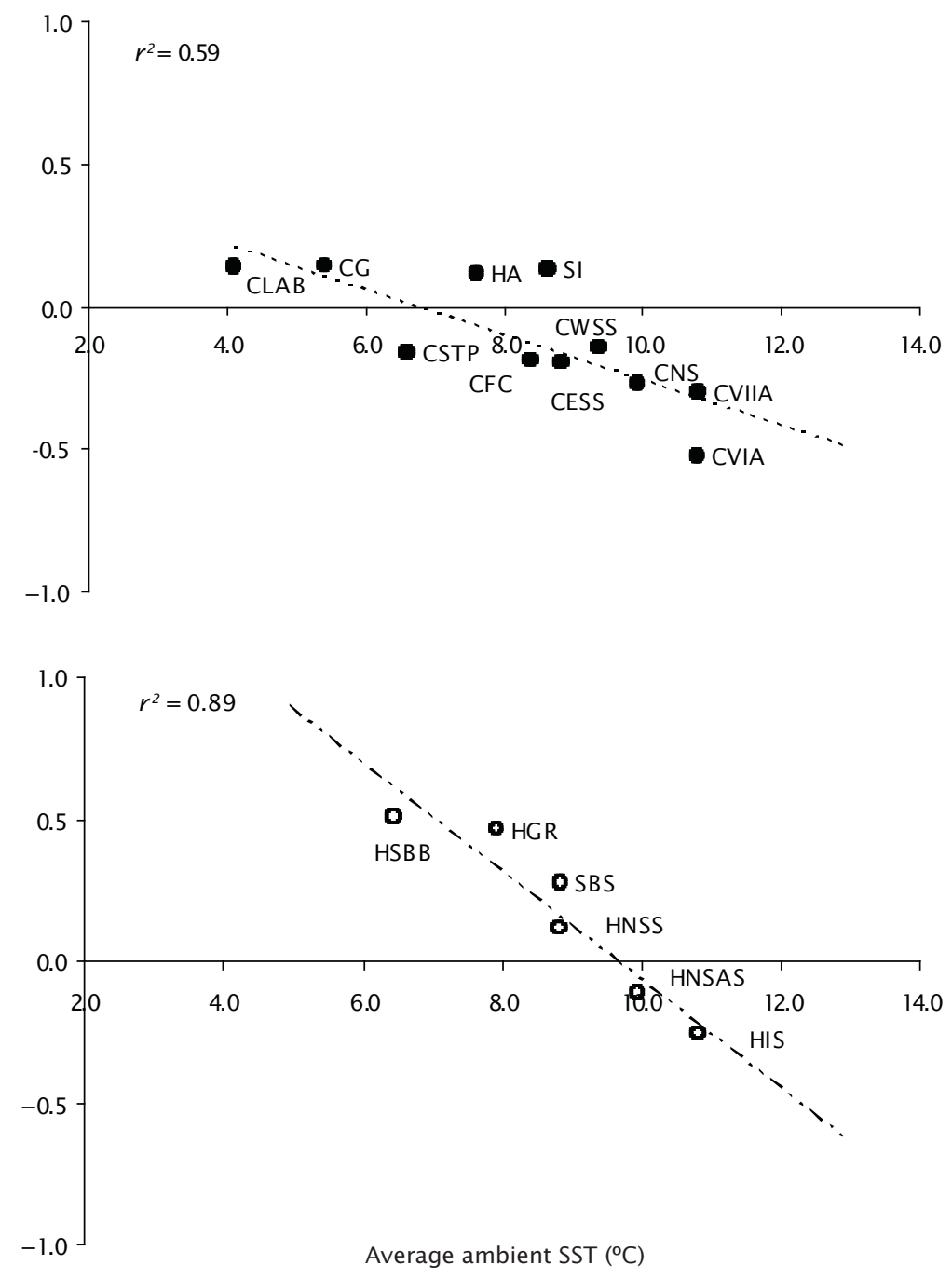

Figure 2. Relationships (both significant at $p<0.01$ ) between the average SST experienced by the stock in its area of distribution during the time series and the correlation coefficient $\left(r^{2}\right)$ of the SST effect on $\boldsymbol{R}_{a}$ (or recruitment depending on the stock) for gadoids (a) and clupeids (b). Only stocks where the relationship between SST and $\boldsymbol{R}_{a}$ (or recruitment depending on the stock) was statistically significant were used in the analysis. 
Table 4. Results of linear regression analysis between $\boldsymbol{R}_{s}$ and SSB; between the residuals of the $R_{s}$-SSB regression (i.e., recruitment anomalies, $\left.R_{a}\right)$ and SST; and between $R$ and SST for all stocks analyzed. ns $=$ not significant relationship. The sign in front of $r^{2}$ indicate whether the relationship is negative or positive.

\begin{tabular}{|c|c|c|c|c|c|c|}
\hline \multirow[b]{2}{*}{ Stock } & \multicolumn{2}{|c|}{$R_{s} \sim S S B$} & \multicolumn{2}{|c|}{$R_{s} \sim S S T$} & \multicolumn{2}{|c|}{$R \sim S S T$} \\
\hline & $r^{2}$ & $p$ & $r^{2}$ & $p$ & $r^{2}$ & $p$ \\
\hline Northeast arctic cod & -0.26 & $<0.01$ & 0.05 & ns & - & - \\
\hline Eastern Baltic cod & -0.18 & $<0.01$ & -0.023716 & ns & - & - \\
\hline Faroe cod & -0.42 & $<0.01$ & -0.047089 & ns & - & - \\
\hline Iceland cod & -0.48 & $<0.01$ & 0.01 & ns & - & - \\
\hline Kattegat cod & -0.09 & ns & - & - & 0.01 & ns \\
\hline North Sea cod & -0.1 & $<0.05$ & -0.269361 & $<0.01$ & - & - \\
\hline Western Baltic cod & -0.06 & ns & - & - & -0.031329 & ns \\
\hline Scotland cod & -0.28 & $<0.01$ & -0.521284 & $<0.01$ & - & - \\
\hline Irish cod & -0.2 & $<0.01$ & -0.297025 & $<0.01$ & - & - \\
\hline Celtic cod & -0.01 & ns & - & - & -0.082369 & ns \\
\hline $\begin{array}{l}\text { Northeast arctic } \\
\text { haddock }\end{array}$ & -0.01 & ns & - & - & 0.12 & 0.02 \\
\hline Faroe haddock & -0.21 & $<0.01$ & -0.054756 & ns & - & - \\
\hline Iceland haddock & -0.12 & ns & - & - & 0.09 & ns \\
\hline North Sea haddock & -0.13 & $<0.05$ & -0.01 & ns & - & - \\
\hline Northeast arctic saithe & -0.52 & $<0.01$ & -0.01 & ns & - & - \\
\hline Rockall haddock & -0.25 & $<0.05$ & -0.083521 & ns & - & - \\
\hline Faroe saithe & -0.45 & $<0.01$ & -0.01 & ns & - & - \\
\hline Iceland saithe & -0.3 & $<0.01$ & 0.13 & 0.02 & - & - \\
\hline North Sea saithe & -0.49 & $<0.01$ & 0.08 & ns & - & - \\
\hline North Sea whiting & -0.29 & $<0.01$ & -0.04 & ns & - & - \\
\hline Scotland whiting & -0.44 & $<0.01$ & -0.01 & ns & - & - \\
\hline Irish whiting & -0.66 & $<0.01$ & -0.01 & ns & - & - \\
\hline Celtic whiting & -0.46 & $<0.01$ & -0.01 & ns & - & - \\
\hline $\begin{array}{l}\text { Eastern Scotian Shelf } \\
\text { cod }\end{array}$ & -0.41 & $<0.01$ & -0.192721 & $<0.01$ & - & - \\
\hline Flemish Cap cod & -0.11 & ns & - & - & -0.186624 & 0.02 \\
\hline Greenland cod & -0.01 & ns & - & - & 0.15 & 0.02 \\
\hline Georges Bank cod & -0.09 & ns & - & - & 0.01 & ns \\
\hline $\begin{array}{l}\text { Labrador Grand Bank } \\
\text { cod }\end{array}$ & -0.02 & ns & - & - & 0.14 & 0.04 \\
\hline $\begin{array}{l}\text { North Gulf of St. } \\
\text { Lawrence cod }\end{array}$ & -0.01 & ns & - & - & 0.08 & ns \\
\hline $\begin{array}{l}\text { Southern Grand Bank } \\
\text { cod }\end{array}$ & -0.01 & ns & - & - & -0.016129 & ns \\
\hline $\begin{array}{l}\text { South Gulf of St. } \\
\text { Lawrence cod }\end{array}$ & -0.35 & $<0.01$ & -0.03 & ns & - & - \\
\hline
\end{tabular}


Table 4. (continued.)

\begin{tabular}{|c|c|c|c|c|c|c|}
\hline \multirow[b]{2}{*}{ Stock } & \multicolumn{2}{|c|}{$R_{s} \sim S S B$} & \multicolumn{2}{|c|}{$R_{s} \sim S S T$} & \multicolumn{2}{|c|}{$R \sim S S T$} \\
\hline & $r^{2}$ & $p$ & $r^{2}$ & $p$ & $r^{2}$ & $p$ \\
\hline St. Pierre Bank cod & -0.31 & $<0.01$ & -0.16 & 0.02 & - & - \\
\hline $\begin{array}{l}\text { Western Scotian Shelf } \\
\text { cod }\end{array}$ & -0.28 & $<0.01$ & -0.142129 & $<0.01$ & - & - \\
\hline Georges Bank haddock & -0.01 & ns & - & - & 0.01 & ns \\
\hline $\begin{array}{l}\text { Western Scotian Shelf } \\
\text { Haddock }\end{array}$ & -0.02 & ns & - & - & 0.08 & ns \\
\hline $\begin{array}{l}\text { Eastern Scotian Shelf } \\
\text { Saithe }\end{array}$ & -0.2 & ns & - & - & 0.13 & ns \\
\hline Central Baltic herring & -0.31 & 0.001 & 0.03 & ns & - & - \\
\hline Celtic Sea herring & -0.15 & $<0.001$ & 0.10 & ns & - & - \\
\hline Gulf of Riga herring & -0.01 & ns & - & - & 0.47 & $<0.001$ \\
\hline Irish Sea herring & -0.14 & 0.015 & -0.25 & $<0.001$ & - & - \\
\hline $\begin{array}{l}\text { Iceland summer } \\
\text { spawning herring }\end{array}$ & -0.1 & ns & - & - & 0.06 & ns \\
\hline $\begin{array}{l}\text { Northern Bothnian } \\
\text { herring (SD 31) }\end{array}$ & -0.33 & 0.003 & 0.01 & ns & - & - \\
\hline $\begin{array}{l}\text { North Sea autumn } \\
\text { spawners herring }\end{array}$ & -0.41 & $<0.001$ & -0.11 & 0.03 & - & - \\
\hline $\begin{array}{l}\text { Norwegian spring } \\
\text { spawning herring }\end{array}$ & -0.11 & 0.001 & 0.12 & 0.01 & - & - \\
\hline $\begin{array}{l}\text { Southern Bothnian } \\
\text { herring (SD 30) }\end{array}$ & -0.01 & ns & - & - & 0.51 & 0.002 \\
\hline $\begin{array}{l}\text { Western Baltic spring } \\
\text { spawners herring }\end{array}$ & -0.62 & 0.001 & 0.08 & ns & - & - \\
\hline $\begin{array}{l}\text { West of Ireland } \\
\text { herring }\end{array}$ & -0.35 & $<0.001$ & 0.04 & ns & - & - \\
\hline $\begin{array}{l}\text { Herring west of } \\
\text { Scotland }\end{array}$ & -0.2 & 0.002 & 0.02 & ns & & \\
\hline Baltic Sea sprat & -0.1 & ns & - & - & 0.28 & 0.003 \\
\hline North Sea sprat & -0.08 & ns & - & - & 0.007 & ns \\
\hline $\begin{array}{l}\text { Newfoundland herring } \\
\text { Bonavista Bay \& } \\
\text { Trinity Bay }\end{array}$ & -0.59 & $<0.001$ & 0.04 & ns & - & - \\
\hline $\begin{array}{l}\text { Newfoundland } \\
\text { herring St. Mary's Bay } \\
\text { \& Placentia Bay }\end{array}$ & -0.33 & 0.001 & 0.01 & ns & - & - \\
\hline $\begin{array}{l}\text { Newfoundland herring } \\
\text { White Bay \& Notre } \\
\text { Dame Bay }\end{array}$ & -0.3 & 0.002 & 0.06 & ns & - & - \\
\hline $\begin{array}{l}\text { South Gulf of St } \\
\text { Lawrence herring } \\
\text { autumn spawners }\end{array}$ & -0.67 & $<0.001$ & 0.01 & ns & - & \\
\hline $\begin{array}{l}\text { South Gulf of St } \\
\text { Lawrence herring } \\
\text { spring spawners }\end{array}$ & -0.64 & $<0.001$ & 0.06 & ns & - & - \\
\hline
\end{tabular}


Table 4. (continued.)

\begin{tabular}{|c|c|c|c|c|c|c|}
\hline \multirow[b]{2}{*}{ Stock } & \multicolumn{2}{|c|}{$R_{s} \sim S S B$} & \multicolumn{2}{|c|}{$R_{s} \sim S S T$} & \multicolumn{2}{|c|}{$R \sim S S T$} \\
\hline & $r^{2}$ & $p$ & $r^{2}$ & $p$ & $r^{2}$ & $p$ \\
\hline $\begin{array}{l}\text { West coast of } \\
\text { Newfoundland herring } \\
\text { spring spawners }\end{array}$ & -0.29 & 0.001 & 0.05 & ns & - & - \\
\hline $\begin{array}{l}\text { West coast of } \\
\text { Newfoundland herring } \\
\text { autumn spawners }\end{array}$ & -0.49 & $<0.001$ & 0.08 & ns & - & - \\
\hline
\end{tabular}

thing. Recruitment success is in a linearized form and therefore, in this different numerical context, properties of $R$ and $R_{s}$ against SSB are mathematical very different and cannot be comparable. Thus, a lack of relationship between $R_{s}$ and SSB does not contradict the fact that a significant relationship has been found for the same stock in other studies using $R$ in absolute numbers (i.e., Rätz and Lloret 2005). Nevertheless, it is also important to stress that part of the observed variability around the relationship between $S S B$ and $R_{s}$ might be dependent on other factors, as structure of the stock (i.e., maternal effect; Marshall et al. 1998), changes in fecundity and conditions of the spawners (Olsen et al. 2005, Scott et al. 2006) and Allee effect (Frank and Brickman 2000), although the investigation of these factors was beyond the scope of the paper.

The historical dynamic of fish stocks is usually related to both natural external factors and anthropogenic influences, among which fishery is generally considered the most important (Myers and Worm 2003). For instance, the high fishing mortality in coincidence of a period of poor recruitment may explain the rapid decline in several herring commercial stocks during the 1960s (Toresen and Oestvedt 2000, Toresen 2001). A similar trend has been observed for some cod stocks in the Northwest Atlantic, with a rapid decline of the populations in coincidence with the development of fisheries techniques intertwined with unfavorable condition for survival of juvenile cod (Drinkwater 2003). A classical explanation is that the coincidence of those two factors accelerated the declining process (Fiksen and Slotte 2002; Toresen 2001). Here we show that the proportion of stocks with a significant SSB effect on $R_{s}$ was significantly larger than the proportion of stocks with a significant SST effect on $R_{a}$ (or $R$ ) for both gadoids and clupeids. Moreover, for gadoids, the strength of the relationships $S S B-R_{s}$ was significantly higher than the strength $S S T-R_{a}$ (or $R$ ). Results as shown here underline that although the effect of temperature on recruitment dynamic is significant for some stocks spawning biomass has generally a much larger impact than climate on the recruitment dynamic of North Atlantic fish. 
There were no significant differences between demersal gadoids and pelagic clupeids concerning the sign of the effect of SST on $R_{a}$ (or $R$ ), although a difference was evident (36\% against $67 \%$ stocks with a positive effect of SST). The lack of significance is possibly due to the low numbers of stocks where a SST effect was found and thus the low sample size used in the Fisher test. Anyhow, a clear relationship was found between the sign of the effect of the SST on $R_{a}$ (or $R$ ) and the average temperature in the distribution area of the stocks, with stocks living in colder areas responding positively to increasing temperature, and vice versa, for both families. Gadoids showed an average ideal SST around $7-8^{\circ} \mathrm{C}$ for optimal $R_{s}$, whereas for clupeid this value was around $9-10^{\circ} \mathrm{C}$. Those results are generally in accordance with other studies for cod (Planque and Frédou 1999, Rätz and Lloret 2005, Drinkwater 2005) (i.e., variation in $R$ with temperature for cod stocks at the border of the species distribution), while the same pattern has never been demonstrated for clupeids. Interestingly, the relationship is much stronger for clupeids compared to gadoids. This might be explained by the existence of a stronger coupling between temperature and recruitment for pelagic fishes, but it could also be due to the fact that SST reflects more closely the ambient temperature experienced by the pelagic stocks.

\section{Conclusions}

It has been argued that resilience to climate changes in unexploited populations is significantly larger than in highly exploited or overfished stocks (Brander 2005). Nevertheless, we showed that spawning biomass play the fundamental role in the regulation of the dynamic of fish stocks. Therefore, although management of exploited fish populations cannot be decoupled from the effect of temperature on their reproductive success, it is likely that the observed shifts in exploited fish communities are mainly the consequences of an unsustainable fishing mortality (Pauly et al. 1997, Myers and Worm 2003, Hutchings 2004) and not of a climate changes.

\section{References}

Bakun A., and K. Broad. 2002. Climate and fisheries: Interacting paradigms, scales and policy approaches. The IRI-IPRC Pacific Climate-Fisheries Workshop, Honolulu, 14-17 November 2001. The International Research Institute for Climate Prediction, IRI Publication IRI-cw/02/1, Columbia Earth Institute, Palisades, NY, 10964, USA. 70 pp.

Beverton, R.J.H. 2002. Man or nature in fisheries dynamics: Who calls the tune? In: E.D. Anderson (ed.), The Raymond J.H. Beverton lectures at Woods Hole, Massachusetts: Three lectures on fisheries science, May 2-3, 1994. NOAA Tech. Memo. NMFS-F/SPO-54, pp. 9-59. 
Beverton, R.J.H., and S.J. Holt. 1995. On the dynamics of exploited fish populations. Chapman and Hall, London. 502 pp.

Bopp, L., et. al. 2001. Potential impact of climate change on marine export production. Global Biogeochem. Cycles 15:81-99.

Brander, K.M. 2005. Cod recruitment is strongly affected by climate when stock biomass is low. ICES J. Mar. Sci. 62:339-343.

Brett, J.R. 1979. Environmental factors and growth. In: W.S. Hoar, D.J. Randall, and J.R. Brett (eds.), Fish physiology. Vol. 8, Bioenergetics and growth. 298 pp.

Cardinale, M., and F. Arrhenius. 2000. The influence of stock structure and environmental conditions on the recruitment process of Baltic cod estimated using a generalized additive model (GAM). Can. J. Fish. Aquat. Sci. 57(12):2402-2409.

Cardinale, M., and J. Hjelm. 2006. Marine fish recruitment variability and climate indices. Mar. Ecol. Prog. Ser. 309:307-309.

Cushing, D.H. 1982. Climate and fisheries. Academic Press, New York.

Drinkwater, K.F. 2003. A review of the role of climate variability in the decline of northern cod. Trans. Am. Fish. Soc. Symp. 32:113-130.

Drinkwater, K.F. 2005. The response of Atlantic cod (Gadus morhua) to future climate change. ICES J. Mar. Sci. 62:1327-1337.

Eide, A., and K. Heen. 2002. Economic impacts of global warming: A study of the fishing industry in North Norway. Fish. Res. 56:261-274.

Fiksen, O., and A. Slotte. 2002. A stock-environment recruitment models for Norwegian spring spawning herring (Clupea harengus). Can. J. Fish. Aquat. Sci. 59:211-217.

Frank, T.K., and D. Brickman. 2000. Allee effects and compensatory population dynamics within a stock complex. Can. J. Fish. Aquat. Sci. 57:513-517.

Hilborn, R., and C.J. Walters. 1992. Quantitative fisheries stock assessment: Choice, dynamics and uncertainty. Chapman and Hall, New York. 570 pp.

Hutchings, J.A. 2004. The cod that got away. Nature 428:899-890.

Houghton, J.H., et al. 2001. Climate change 2001. Cambridge University Press, Cambridge. 944 pp.

Insightful Corporation. 2005. S-PLUS 7 for Windows. Insightful Corporation, Seattle.

Loukos, H., P. Monfray, L. Bopp, and P. Lehodey. 2003. Potential changes in skipjack tuna (Katsuwonus pelamis) habitat from a global warming scenario: Modelling approach and preliminary results. Fish. Oceanogr. 12:474-482.

MacKenzie, B.R., A.M. Myers, and K.G. Bowen. 2003. Spawner-recruit relationships and fish stock carrying capacity in aquatic ecosystem. Mar. Ecol. Prog. Ser. 248:209-220.

Marshall, J.Y., et al. 2001. North Atlantic climate variability: Phenomena, impacts and mechanisms. Int. J. Climatol. 21:1863-1898. 
Marshall, T., O.S. Kjesbu, N.A. Yaragina, P. Solemdal, and ø. Ulltang. 1998. Is spawner biomass a sensitive measure of the reproductive and recruitment potential of northeast arctic cod? Can. J. Fish. Aquat. Sci. 55:1766-1783.

Myers, R.A. 1998. When do environment-recruitment correlations work? Rev. Fish Biol. Fish. 8:285-305.

Myers, R.A., and N.J. Barrowman. 1996. Is fish recruitment related to spawning abundance? Fish. Bull. U.S. 94:707-724.

Myers, R.A., and B. Worm. 2003. Rapid worldwide depletion of predatory fish communities. Nature 423:280-283.

Olsen, E.M., G.R. Lilly, M. Heino, M.J. Morgan, J. Brattey, and U. Dieckmann. 2005. Assessing changes in age and size at maturation in collapsing populations of Atlantic cod. Can. J. Fish. Aquat. Sci. 62:811-823.

Ottersen, G., K. Michealsen, and O. Nakken. 1998. Ambient temperature and distribution of north-east arctic cod. ICES J. Mar. Sci. 55:67-85.

Pauly, D., V. Christensen, J. Dalsgaard, R. Froese, and F. Torres. 1997. Fishing down marine food webs. Science 279:860-863.

Planque, B., and T. Frédou. 1999. Temperature and the recruitment of Atlantic cod (Gadus morhua). Can. J. Fish. Aquat. Sci. 56:2069-2077.

Rätz, H-J., and J. Lloret. 2005. Long-term variability of growth and recruitment of cod (Gadus morhua) off Greenland. ICES J. Mar. Sci. 62:1310-1321.

Ricker, W.E. 1954. Stock and recruitment. J. Fish. Res. Board Can. 11:559-623.

Sarmineto, J.L., T.M.C. Hughes, R.J. Stouffer, and S. Manabe. 1998. Simulated response of the ocean carbon cycle to anthropogenic climate warming. Nature 393:245-249.

Scott, B.E., G. Marteinsdottir, G.A. Begg, P.J. Wright, and O.S. Kjesbu. 2006. Effects of population size/age structure, condition and temporal dynamics of spawning on reproductive output in Atlantic cod (Gadus morhua). Ecol. Model. 191:383-415.

Statsoft Inc. 2003. Statistica version 6. Statsoft Inc.

Steele, J.H. 1985. A comparison of terrestrial and marine ecological systems. Nature 313:355-358.

Stige, L.C., G. Ottersen, K. Brander, K.S. Chan, and N.C. Stenseth. 2006. Cod and climate: Effect of the North Atlantic Oscillation on recruitment in the North Atlantic. Mar. Ecol. Prog. Ser. 325:227-241.

Toresen, R. 2001. Spawning stock fluctuations and recruitment variability related to temperature for selected herring (Clupea harengus) stocks in the North Atlantic. In: F. Funk, J. Blackburn, D. Hay, A.J. Paul, R. Stephenson, R. Toresen, and D. Witherell (eds.), Herring: Expectations for a new millennium. Alaska Sea Grant, University of Alaska Fairbanks, pp. 315-334.

Toresen, R., and O.J. Oestvedt. 2000. Variation in abundance of Norwegian spring-spawning herring (Clupea harengus, Clupeidae) throughout the 20th century and the influence of climatic fluctuations. Fish Fish. 3:231-256. 
